\title{
The Assistance to Develop Creativity in Early Childhood (TK) Using Plasticine Amid The Covid-19 Pandemic.
}

\section{Az Zahro Miftakhuljanah, Sugiyanto}

Universitas Sebelas Maret

azzahr.kh1099@gmail.com

\section{Article History}

accepted 31/08/2020

approved 22/09/2020

published 28/10/2020

\begin{abstract}
During the Covid-19 pandemic, almost all schools carried out online learning, but children became bored and played more. It will be more dangerous if children play outside the home environment and hang out freely with their friends so that they have the potential to contract corona. UNS Covid-19 KKN has an alternative way of playing that is interesting and develops creativity, namely the play with plasticine program. This program is implemented in Kretek Village, Karang Sembung RT 03/04, Kebumen Regency. The participants consisted of 4 children, 1 kindergarten teacher and 1 parent. In the implementation, the children were divided into groups, but each child made his own work according to the theme. Children are able to form plasticine works with themes, including food, fruits, a zoo atmosphere, and so on. The results of this program show: 1) children's creativity can develop, 2) play activities outside the home environment are reduced, 3) learning according to health protocols, namely adjusting distance in interactions 4) experience exchange occurs 5) parents are motivated in learning to guide children learning while playing.
\end{abstract}

Keywords: Creativity, kindergarten children, Play, Plasticine, Covid-19

\begin{abstract}
Abstrak
Selama pandemi Covid-19, hampir semua sekolah melakukan pembelajaran daring, namun anak menjadi bosan dan lebih banyak bermain. Akan lebih berbahaya jika anak-anak bermain di luar lingkungan rumah dan bergaul bebas dengan temannya sehingga berpotensi tertular corona. KKN UNS Covid-19 mempunyai alternatif cara bermain yang menarik dan mengembangkan kreatifitas yaitu program bermain dengan plastisin. Program ini dilaksanakan di Desa Kretek, Karang Sembung RT 03/04, Kabupaten Kebumen. Peserta terdiri dari anakanak 4 orang, guru TK 1 orang dan orangtua 1 orang. Dalam pelaksanaannya anak-anak dibagi dalam kelompok namun masing-masing anak membuat karya sendiri sesuai dengan tema. Anak-anak mampu membentuk karya plastisin dengan tema, antara lain makanan, buahbuahan, suasana kebun binatang, dan sebagainya. Hasil program ini menunjukkan: 1) kretaifitas anak dapat berkembang, 2) kegiatan bermain di luar lingkungan rumah berkurang, 3) belajar sesuai protocol kesehatan yaitu mengatur jarak dalam berinteraksi 4) terjadi tukar pengalaman 5) orangtua termotivasi dalam belajar membimbing anak belajar sambil bermain.

Kata kunci: Kreativitas, anak usia TK, Bermain, Plastisin, Covid-19
\end{abstract}

Social, Humanities, and Education Studies (SHEs): Conference Series https://jurnal.uns.ac.id/shes

p-ISSN 2620-9284

e-ISSN 2620-9292 


\section{PENDAHULUAN}

Pendidikan merupakan unsur penting bagi masyarakat khususnya bagi anakanak yang memiliki kewajiban untuk mengenyam wajib pendidikan minimal selama 9 tahun. Pada era pandemi Covid-19 hampir semua sekolah melakukan pembelajarn dengan sistem daring (dalam jaringan) sering disebut learning from home (LFH), hal ini membuat anak mejadi tidak fokus dalam belajar karena kondisi yang kurang kondusif. Mereka lebih banyak bermain hingga banyak tugas yang di berikan sekolah terbengkalai. Dengan kondisi seperti ini, banyak orangtua kesulitan menyediakan kesempatan pendidikan yang optimal bagi anak-anak mereka. (Yudhoyono, 2020)

Anak usia dini yang masih ingin selalu bermain menjadi agen pertama dalam ketidakseriusan belajar dirumah secara daring, sehingga sangat membutuhkan modifikasi proses belajar yang tepat. Dalam rangka mengembangkan kreativitas usia anak dini belajar sambil bermain adalah modifikasi belajar yang baik yang di lakukan oleh guru, orangtua, maupun masyarakat sekitar. Menurrut Munandar (Makulua, 2015), kreativitas merupakan suatu kemampuan yang dimiliki oleh setiap anak dalam rangka menghasilkan suatu hal baru baik berupa gagasan atau ide, maupun karya-karya yang sifatnya nyata yang memiliki keberbedaan dari bentuk atau sifat aslinya atau yang sudah ada sebelumnya, yang dapat dikreasikan menjadi bentuk-bentuk baru dan berbeda. Masa perkembangan anak usia dini adalah masa yang paling tepat untuk mengembangkan semua potensi yang dimiliki anak. Salah satu potensi yang perlu dikembangkan adalah tentang wawasan dan rasa seni anak. Kesenian merupakan salah satu potensi dasar anak sebagai bentuk dari kecerdasan jamak (multiple intelligence). Melalui pengembangan potensi seni anak berarti juga mengembangkan kecerdasannya. Jika potensi ini tidak dikembangkan sejak dini, maka masa emas pengembangan potesi tersebut akan terlewat begitu saja, meskipun dapat dikembangkan pada tahun-tahun sesudahnya, namun hasil yang dicapai tidak akan seoptimal apabila dikembangkan pada masa emasnya. Anak sebagai mahluk yang memiliki perasaan dan pikiran, mempunyai kebutuhan untuk menyatakan perasaan dan pikirannya dengan berbagai macam cara menurut keinginannya sendiri. (Mushonifah, 2013)

Menurut teori kreativitas guilford bahwa suatu kreativitas di dalam diri anak berhubungan dengan proses berpikir secara konvergen dan divergen (Marlina \& Mayar, 2020). Adapun faktor penghambat dan fator pendukung dari pekembangan kreativitas anak. Faktor pendukung kperkembangan kreativitas anak anatara lain: (1) Fasilitas belajar dan bermain dari anak yang disiapkan untuk menstimulasi anak dalam berekperimen dan mencoba hal-hal baru, (2) Lingkungan belajar yang asri, nyaman dan sesuai dengan kebutuhan anak, (3) Strategi pengajar untuk mendorong kreativitas anak terbangun, (4) Kolaborasi antara orang tua dan masyarakat dalam mendorong kretivitas anak. Selain itu faktor penghambat perkembangan kreativitas anak antara lain : (1) Berasal dari dalam diri anak, (2) Pola pendidikan yang diberikan kepada anak, (3) Interaksi sosial anak yang tidak efektif, (4) Pandangan dari budaya, lingkungan belajar dan bermain anak yang tidak kondusif (Amrullah, Silmi, dkk, 2018).

Menurut Hurlock (dalam Sit, 2016) manfaat dari kreativitas bagi kehidupan anak antara lain: (1) Kreativitas memberi anak-anak kesenangan dan kepuasan pribadi; (2) Menambah bumbu dalam permainannya pusat kegiatan hidup mereka; (3) Membantu anak-anak untuk mencapai keberhasilan di bidang yang berarti bagi mereka; (4) Kreativitas memiliki nilai yang sangat penting bagi tumbuh kembangnya anak contohnya nilai kepemimpinan. Menurut Amabile (Priyanto, 2014) keberhasilan kreativitas anak adalah ketika persimpangan (intersection) antara keterampilan anak didalam bidang tertentu (domain skills), keterampilan berpikir, bekerja kreatif, dan dan menimbulkan motivasi instrinsik. Sehingga sekolah biasanya melaksanakan pembelajaran pengembangan aspek kreativitas anak, namun adanya kondisi pandemi Covid-19 menjadi sangat terhambat dengan adanya sistem LFH yang sekarang di 
berlakukan. Oleh karena itu berdasarkan hasil diskusi dengan salah satu guru TK Pertiwi 14.26.10 Kretek, persoalan orang tua yang belum dapat membimbing anaknya secara penuh ketika belajar dirumah menggunakan sistem LFH khusunya pada pembelajaran pengembangan kreativitas. Hal ini membuat beberapa guru menjadi kebingungan dalam penyampaian penugasan terkait aspek kreativitas anak.

Program pengabdian ini yaitu "Pendampingan Mengembangkan Kreativitas Anak Usia Dini (TK) Menggunakan Media Plastisin Di Era Pandemi Covid-19" bertujuan untuk membantu kesulitan guru dalam melakukan pendampingan kepada anak untuk salah satu pembelajaran aspek kreativitas yang menggunakan media plastisin. Kegiatan ini berfokus pada belajar sambil bermain dimana anak mampu mengembangkan kreativitasnya menggunakan media plastisin untuk menghasilkan karya-karya yang baru atau berbeda dengan yang sebelumnya dengan cara melakukan inovasi-inovasi baru atau modifikasi terhadap karya yang sama dengan karya sebelumnya atau aslinya.kegiatan ini juga bertujuan untuk meminimalisir kegiatan bermain anak di luar rumah pada kondisi pandemi Covid-19. Kebermanfaatan kegiatan ini tidak hanya dirasakan pada guru namun pada orang tua yang merasa terbantu dalam membimbing anak-anak mereka.

\section{METODE}

Program pengabdian ini dilakukan di Desa Kretek, Dukuh Karang Sembung RT 03 RW 04 Desa, Kecamatan Rowokele, Kabupaten Kebumen selama 45 hari terhitung dari pertengahan bulan Mei sampai akhir bulan Juni 2020, namun untuk pelaksanaannya satu minggu sekali. Kegiatan progam pengabdian ini dilaksanakan berdasarkan melihat realita yang ada di masyarakat terkait kesulitan guru dalam memberikan pendampingan pembelajaran pada anak didiknya, orang tua yang masih kurang dapat mendampingi proses belajar anak pada saat pandemi Covid-19 dengan sistem LFH, dan masih banyaknya anak yang melakukan kegiatan bermain diluar rumah tanpa mengguankan alat pelindung diri seperti masker dan berkumpul dengan teman-temannya tanpa membatasi jumlah, penjagaan jarak, dan sebagainya. Dengan adanya pelaksanaan kegiatan ini anak-anak diajak untuk belajar memahami kondisi yang sedang terjadi di era pandemi Covid-19 saat ini.

\section{HASIL DAN PEMBAHASAN}

Kreativitas merupakan kemampuan baru yang di bawa dalam kehidupan, kreativitas juga menjadi penyalur ilham atau inspirasi yang kemudian dituangkan kedalam gagasan yang memiliki bentuk yang berbeda-beda dimana kreativitas tersebut menjadi bentuk kemajuan dari pola pikir anak (Anhusadar, 2016). Kreativitas anak usia dini merupakan sarana mengembangkan potensi-potensi sejak dini sehingga mereka dapat berkembang secara wajar sebagai anak. Di era pandemi Covid-19 salah satu cara mengembangkan kreativitas anak yaitu melalui belajar sambil bermain yang tetap dilakukan di dalam rumah, bermain mengguanakan media plastisin adalah contoh sarana mengembangkan kreativitas pada anak. Menurut Mulyasa (Holis, 2016) proses belajar pada hakekatnya mengembangkan aktivitas dan kreativitas anak melalui interaksi dan pengalaman belajar dimana dapat dilakukan dengan cara belajar sambil bermain.

Menurut M. Lansing (Mushonifah, 2013), kegiatan bermain Plastisin ini dilakukan dengan cara membentuk, mewarnai, dan memberi warna sehingga menimbulkan bentuk. Bermain plastisin merupakan kegiatan anak usia dini. Kegiatan bermain plastisin seperti halnya menyanyi dapat dilakukan dengan kesadaran penuh berupa maksud dan tujuan tertentu maupun sekedar membuat bentuk tanpa arti. Pendampingan mengembangkan kreativitas anak usia dini (TK) di era pandemi Covid19 ini dilaksanakan dengan mula-mula membentuk kelompok bermain dari usia dini 
(TK) yang terdiri dari 4-6 anak, kemudian pelaksanaan berada di dalam rumah dan menggunakan media plastisin yang memiliki berbagai warna. Selanjutnya kelompok bermain yang terdiri dari 4-6 anak usia dini (TK) diberikan tema misalnya tema tentang makanan, buah-buahan, suasana kebun binatang, dan sebagainya. Setelah itu mereka secara sendiri-sendiri membuat berbagai bentuk atau karya sesuai tema yang diberikan namun mengelompok dengan berjarak-jarak, dan hasil karyanya dikumpulkan dalam bentuk kelompok. Dampak yang dihasilkan dari adanya kegiatan pendampingan pengembangan kreativitas anak usia dini (TK) menggunakan media plastisin di era pandemi Covid-19 yaitu anak menjadi tetap dapat mengambangkan kreativitasnya baik karena tugas dari guru di sekolah maupun sebagai kegiatan belajar sambil bermain sehingga kreativitas akan selalu terasah memunculkan ide-ide, inovasiinovasi, maupun karya-kaya baru maupun karya hasil modifikasi dari yang telah ada sebelumnya.

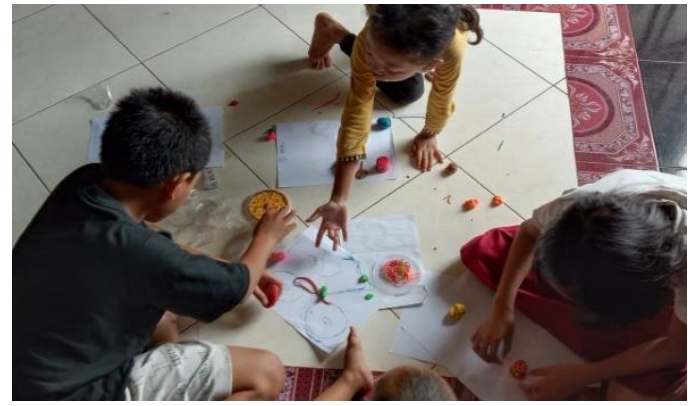

Gambar 1. Proses Kegiatan Pengembangan Kreativitas Tema Makanan dan Buah-buahan

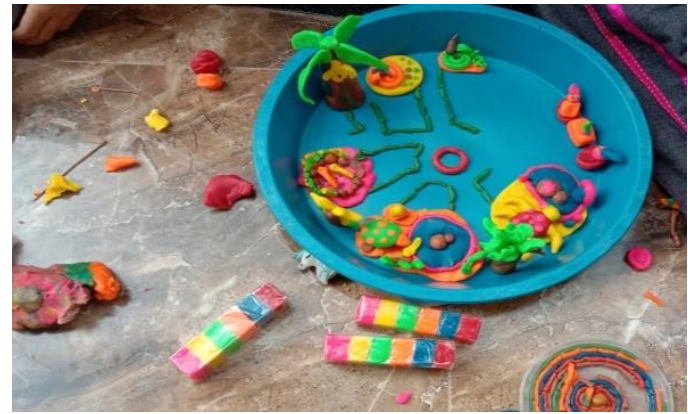

Gambar 2. Proses Kegiatan Pengembangan Kreativitas Tema Suasana Kebun Binatang

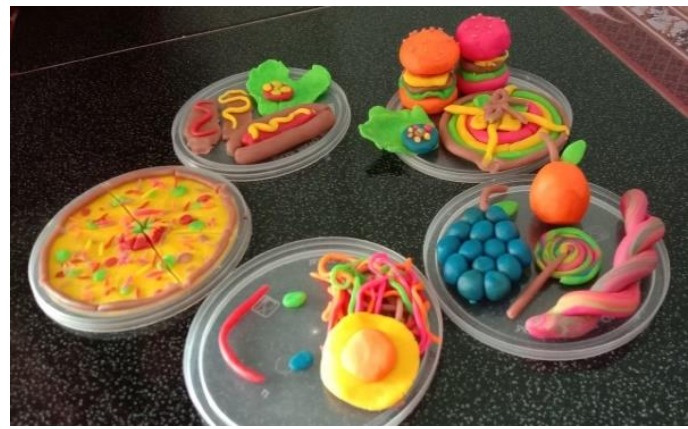

Gambar 3. Hasil Kegiatan Pengembangan Kreativitas Tema Makanan dan Buah-buahan 


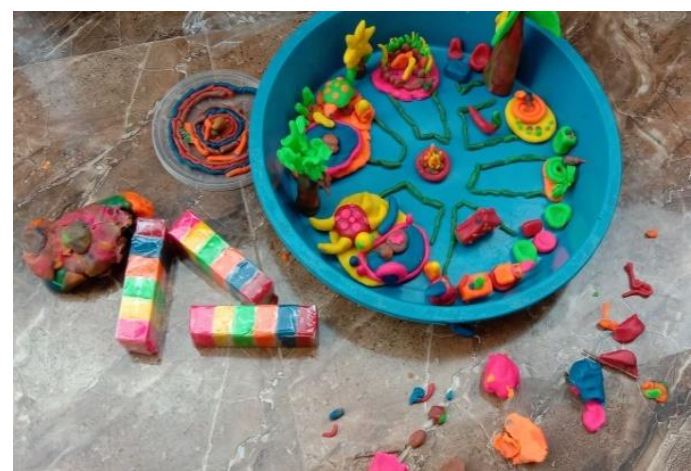

\section{Gambar 4. Hasil Kegiatan Pengembangan Kreativitas Tema Suasana Kebun Binatang}

Gambar 1 dan gambar 2 merupakan proses dari kegiatan pengembangan kreativitas pada anak dengan dua tema yang berbeda yaitu tema makanan dan buahbuahan, serta tema suasana kebun binatang. Sedangkan pada gambar 3 dan gambar 4 merupakan hasil dari pengembangan kreativitas oleh anak-anak. Dari hasil karya anak-anak mengembangkan kreativitas menggunakan media plastisin dapat terlihat aspek kreativitas yang dimiliki dari masing-masing anak.

Bermain dengan plastisin yang dilakukan oleh anak usia dini dilakukan secara berkemlompok ini sangat memberikan kemajuan dalam pola pikir mereka. Setiap anak yang satu degan yang lain selalu memiliki ide masing-masing untuk membuat bentuk yang berbeda-beda. Mengulang-ulang kembali apabila hasilnya kurang sesuai dengan harapan. Contohnya dalam tema makanan salah satu anak yang yang membuat bentuk makanan pizza, ketika hasil akhir belum maksimal terlihat seperti makanan pizza, anak tersebut selalu mengguanakan caranya untuk mengulang dan memperbaiki hasilnya agar menjadi bentuk makanan pizza sungguhan.

Tema makanan dan buah-buahan merupakan tema yang diambil sesuai dengan keinginan dari anak-anak. Pada tema ini mereka mencontoh makananmakanan tertentu untuk di bentuk yangsama dan sesuai dengan bentuk aslinya, sesekali mereka juga menumbuhkan inovasi-inovasi baru didalamnya. Media plastisin yang dibentuk anak-anak menghasilkan beberapa bentuk makanan seperti pizza, hamburger,anggur, jeruk, permen lolipop, telur mata sapi, mie, sosis yang mereka akreasikan dalam bentuk hot dog, dan lain sebagainya. Sedangkan pada tema kebun binatang mereka bersama-sama mengkreasikan media plastisin menjadi bentuk dengan suasana kebun binatang. Dalam suasana kebun binatang tersebut mereka membuat taman, bunga, hewan (kura-kura, ikan, dan lain-lain), tanaman/ pohon, tempat peristiraharan (ada kursi dan meja), orang sebagai penjaga dan pengunjung, dan sebagainya. Dari hasil karya mereka sangat terlihat bagaimana aspek kreativitas yang ada pada diri anak.

\section{SIMPULAN}

Kesimpulan : Kegiatan program pendampingan mengembangkan kreativitas anak usia dini (TK) yaitu kegiatan dengan berbentuk kelompok bermain yang terdiri dari 4-6 anak usia dini (TK) yang dilaksanakan di dalam rumah menggunakan media plastisin dengan memberikan tema-tema untuk menghasilkan karya yang jelas misalnya tema tentang makanan, buah-buahan, suasana kebun binatang dan sebgainya. Kegiatan ini dilaksanakan dalam rangka mengembangkan aspek kreativitas anak usia dini sekaligus sebagai pendampingan pembelajaran yang di berikan oleh guru di sekolahnya terkait pembelajaran mengenai aspek pengembangan kreativitas pada diri anak. Kebermanfaatan kegiatan ini tidak hanya dirasakan pada penulis, guru yang terlibat, namun pada orang tua yang merasa terbantu dalam membimbing anakanak. 


\section{DAFTAR PUSTAKA}

Amrullah, Silmi, Dkk. (2018). Studi Sistematik Aspek Kreativitas Dalam Konteks Pendidikan. Jurnal Ilmiah Psikologi Volume 5, Nomor 2, 2018 : 187-200. elSSN 2502-2903, pISSN: 2356-3591. DOI: 10.15575/psy.v5i2.3533

Anhusadar, LO. (2016). Kreativitas Pendidik Di Lembaga PAUD. Kendari : IAIN Kendari, Vol 9 No 1, diakses pada tanggal 27 September 2020

Holis, A. (2016). Belajar Melalui Bermain Untuk Pengembangan Kreativitas Dan Kognitif Anak Usia Dini. Jurnal Pendidikan Universitas Garut Volume 09, No 01, 2016: 23-37. ISSN 1907-923X

Makulua, K. (2015). Strategi Guru Dalam Meningkatkan Kreativitas Anak Usia Taman Kanak-Kanak. KENOSIS Volume 1, No 1, 2015: hal 89-107

Marlina L, Mayar F. (2018). Pelaksanaan Keiatan Finger Painting Dalam Mengembangkan Kreativitas Seni Anak Di Taman Kanak-Kanak. Jurnal Pendidikan Tambusai Volume 4, Nomor 2, 2018: 1018-1025. EISSN 2614-3097, pISSN: 2614-6754.

Mushonifah, Leni. (2013). "Meningkatkan Kreativitas Anak Usia Dini Melalui Bermain Plastisin Di RA Khoirul Ummah" dalam https://www.ejurnal.com/2015/06/meningkatkan-kreativitas-anak-usia-dini.html, diakses 5 Juli 2020

Muzayyinah. (2014). "Meningkatkan Kreativitas Anak Melalui Metode Bermain Plastisin" dalam https://muzayyinah5.blogspot.com/, diakses 5 Juli 2020

Priyanto, A. (2014). Pengembangan Kreativitas Pada Anak Usia Dini Melalui Aktivitas Bermain. Jurnal IImiah Guru "COPE", No 02: 2014, hal 41-47

Rochayah, Siti. (2012). "Meningkatkan Kreativitas Anak Melalui Metode Bermain Plastisin Pada Siswa Kelompok B TK Masyithoh 02" dalam https://sitirochayahroin.files.wordpress.com/2012/12/1-siti-r.pdf, diakses 5 Juli 2020

Sit, Masganti., dkk. (2016). Pengembangan Kreativitas Anak Usia Dini, Teori Dan Praktik. Medan: Perdana Publishing

Yudhoyono, AH. (2020, 8 Mei). "Pendidikan Indonesia Di Tengah Pandemi Covid-19". Media Indonesia, hal 